\title{
Anaemia Health Literacy of Community Members and Health Practitioners Knowledge of Best Practice Guidelines in a Remote Australian Aboriginal Community
}

\author{
Thérèse Kearns", Felicity Ward, Stefanie Puszka, Roslyn Gundjirryirr, Bonnie Moss, Ross Bailie \\ Menzies School of Health Research, Charles Darwin University, Darwin, Australia
}

Copyright $(2017$ by authors, all rights reserved. Authors agree that this article remains permanently open access under the terms of the Creative Commons Attribution License 4.0 International License

\begin{abstract}
Anaemia is a critical public health problem in Australian Aboriginal and Torres Strait Islander people for which the health literacy of community members and health practitioners is unknown. Worldwide, pregnant women and children have the highest anaemia rates and are the major groups targeted for screening and intervention programs. In the Northern Territory, Australia, $15 \%$ of Aboriginal mothers are anaemic during pregnancy and up to $25 \%$ of children aged 0-5 years are anaemic, with the highest prevalence of $31 \%$ identified in those aged 6-11 months. Anaemia can have adverse effects on physical and cognitive development in the early years and has long-term implications for the development of chronic diseases later in life. The aim of this study was to assess anaemia health literacy of community members and health practitioner's knowledge of anaemia best practice guidelines in a remote Aboriginal community where English is not the first language. Focus groups and individual interviews were conducted with 39 community members and 12 health practitioners. Among community members there were mixed levels of anaemia health literacy with the majority assessed as having 'good' literacy. Health practitioners had a 'very good' level of anaemia knowledge that was excellent for one group.
\end{abstract}

Keywords Anaemia, Anaemia Knowledge, Anaemia Health Literacy, Health Practitioners, Best Practice Guidelines

\section{Introduction}

Anaemia is a critical public health problem in Australian Aboriginal and Torres Strait Islander people [1] for which the health literacy of community members and health practitioners is unknown.[2] Worldwide pregnant women and children have the highest anaemia rates and are the major groups targeted for screening and intervention programs. [3] In the Northern Territory (NT), Australia, 15\% of Aboriginal women are anaemic during pregnancy and up to $25 \%$ of Aboriginal children aged 6 months- 5 years; with the highest prevalence of $31 \%$ identified in those aged 6-11 months.[4,5] Anaemia in pregnancy has physical and mental health consequences for the mother and predisposes the unborn child to prematurity, low birth weight (LBW), low iron stores at birth and to early development of anaemia.[6,7] Childhood anaemia has immediate and long-term implications affecting health, development, cognition, learning ability and economic productivity.[6,8,9]

Health literacy is the understanding of health information that people have and how they apply that information to their everyday lives.[10] In the NT, anaemia health literacy of Aboriginal people is unknown, but due to the remoteness of their living locations is assumed to be low.[2] Low health literacy levels for other conditions, in many other countries, have been associated with a higher use of health services and poorer health outcomes, [11] Increases in health literacy have been shown to improve health outcomes and reduce disparities and inequalities in health status.[11]

Reports from the ABCD National Partnership Project that monitor best practice guideline implementation and trends, indicate that specified anaemia screening, treatment, follow-up and brief interventions for children over three months of age are poorly implemented, and did not improve over the period 2007-2013, despite an increase in continuous quality improvement processes.[12, 13] Other studies have identified that poor organization, inadequate staffing, [14] unacceptable standards of infant care and parent support, no relationship between volume and acuity of presentations and staff numbers with the required skills, are significant barriers to health care delivery. What has not been assessed is community members' anaemia health literacy and how this knowledge compares with anaemia prevention and management guides.

The aim of this study was to assess anaemia health literacy 
of community members and health practitioner's knowledge of anaemia best practice guidelines to establish if these factors could be contributing to the high childhood anaemia prevalence and the poor implementation and uptake of anaemia best practice guidelines.

\section{Materials and Methods}

\subsection{Study Location}

This study was conducted in a remote Aboriginal community with a population of 2000 .[15] The community is located on a tropical island where the temperature ranges from $15-35^{\circ} \mathrm{C}$ and humidity from $20-95 \%$. [16] The main language spoken is Djambarrpuyngu however, there are up to 12 other languages used in this community.[17] The community has two primary health care services, a school teaching classes from preschool to Year 12 and three food stores each with a takeaway attached.

\subsection{Research Team}

The research team included a Project Manager (PM), Remote Area Nurse/Midwife (RAN/M), Aboriginal Health Practitioner (AHP) and Aboriginal Community Worker (ACW) who had completed the Certificate II in Child Health Research (70131NT); a training program developed for national accreditation by author Kearns. The research team received training in conducting focus groups and interviews by author Moss. The team had extensive experience in conducting research in Aboriginal communities and their employer, Menzies School of Health Research, has over 30 years' experience working with Aboriginal people to improve health outcomes and a long standing track record in working with and building the capacity of community based researchers.[18-20]

\subsection{Recruitment}

Participants were recruited by the RAN/M, AHP and ACW. Community members who had participated in the trial of using an electronic food diary [20] and had provided written informed consent to be interviewed or be part of a focus group, were approached to confirm their participation and that of other household members. Health practitioners were approached at their place of work and were interviewed on the day they provided written informed consent.

\subsection{Study Design and Data Collection}

This was a mixed methods study using focus groups and individual interviews to obtain responses to a semi structured questionnaire on anaemia that was quantified using a rating system. Questions were developed by the authors Kearns (RAN/M), Ward (PM), Gundjirryirr (ACW), Puszka and the
AHP to elucidate responses on the participant's understanding of the definition, symptoms, prevention and treatment of anaemia. The questions were mapped to the Central Australian Remote Practitioners Association (CARPA) standard treatment manual [6] for health practitioners and publically available anaemia fact sheets produced by Kidney Australia [21] and Raising Children Network. [22]

The AHP and ACW conducted interviews and focus groups in local language after translating the questions from English, for community members and health practitioners who did not have English as their first language. Interviews and focus groups were videoed or audio recorded. Community members and health practitioners chose whether they wanted an individual interview or to be part of a focus group. The RAN/M and AHP interviewed and conducted focus groups with the health practitioners at their place of work and the PM, AHP and ACW conducted the interviews and focus groups with community members at their local residence.

There was no time limit in which responses had to be provided however, if it appeared that the person or group did not understand the question then the researcher moved on to the next question. Several questions were asked in a slightly different way for community members to help elicit responses (e.g. Results - Q3 \& Q6 and, Q4 \& Q7). The AHP and ACW often started with a story relating to the question before they asked the question directly, and allowed time for participants to process the information before responding; a common practice when conducting research in Aboriginal communities to respect cultural norms.[23]

Interviews and focus groups conducted in the local language were translated into written English by the AHP and ACW. The PM transcribed the English interviews from video or voice recordings into written English. The community member responses were then de-identified by the PM and collated into two documents: 1) by interview or focus group - to quantify the health literacy level of each interview or focus group and b) by question - to conduct a thematic analysis of responses. The health practitioners' responses were de-identified by the PM and collated by question to quantify the knowledge of the anaemia best practice guidelines.

\subsection{Data Analysis}

To quantify and rate the anaemia health literacy responses of community members and knowledge of the anaemia best practice guidelines among health practitioners' two scoring matrices were developed. The scoring matrix for the community members was developed by the RAN/M and PM from publicly available fact sheets, Kidney Australia [21], Raising Children Network [22] and the NT Department of Health Remote Atlas. [24] The scoring matrix for health practitioners was developed by RAN/M and AHP using the CARPA Standard Treatment Manual (Table 1) and CARPA Reference Manual. [6, 25] 
Table 1. Haemoglobin $(\mathrm{Hb})$ result and what to do.[25]

\begin{tabular}{|c|c|c|}
\hline $\mathrm{Hb}$ result & What it means & What to do \\
\hline $\begin{array}{c}\text { Low for age } \\
\text { but } \geq 90 \mathrm{~g} / \mathrm{L}\end{array}$ & $\begin{array}{c}\text { Likely to be iron } \\
\text { deficient }\end{array}$ & $\begin{array}{c}\text { Give oral or IM iron } \\
\text { If hookworm in community }- \\
\text { give albendazole for } 3 \text { days } \\
\text { Follow-up after } 4 \text { wks } \\
\text { If } \mathrm{Hb}<100 \mathrm{~g} / \mathrm{L}-\text { medical } \\
\text { review }\end{array}$ \\
\hline$<90 \mathrm{~g} / \mathrm{L}$ & $\begin{array}{c}\text { May be other cause } \\
\text { of anaemia }\end{array}$ & $\begin{array}{c}\text { If } \mathrm{Hb}<80 \mathrm{~g} / \mathrm{L} \text { urgent medical } \\
\text { review }\end{array}$ \\
& \multicolumn{2}{|c|}{$\begin{array}{c}\text { Treat as above and give folic } \\
\text { acid }\end{array}$} \\
& $\begin{array}{c}\text { Full blood count } \\
\text { Follow-up after } 4 \mathrm{wks}\end{array}$ \\
\hline \multicolumn{2}{|c|}{ Encourage healthy eating and diet high in iron } \\
\hline
\end{tabular}

The interview and focus group responses for each question were independently assessed against the scoring matrices into five different levels of health literacy or knowledge by the RAN/M and PM: 1=Poor, 2=Fair, 3=Good, $4=$ Very Good, 5=Excellent. The median of each question was calculated to assess the knowledge obtained from that question. The group or individual interview was then given an overall score from the questions asked and categorized into a summary rating of health literacy or knowledge: $0-20 \%=$ Poor, $21-40 \%=$ Fair, $41-60 \%=$ Good, $61-80 \%=$ Very Good, $81-100 \%=$ Excellent. The scores of the RAN/M and PM were compared for inter-rater reliability and concordance within the same scoring category was achieved for each of the questions.

During the research translation of the study findings an extra question was asked of health practitioners about what they would do if they were seeing an individual with $\mathrm{Hb} 108$ $\mathrm{g} / \mathrm{L}$. The responses were collated and presented as the number and percentage of health practitioners who chose each response.

\subsection{Ethics and Funding}

Ethics approval was received from Human Research Ethics Committee of the Northern Territory Department of Health and Menzies School of Health Research (HREC-2012-1898). Funding was provided by the Lowitja Institute (12-250).

\section{Results}

\subsection{Community Members}

Eight focus groups and two individual interviews were conducted with 39 adult community members of which 32 $(82 \%)$ were female (Table 2$)$. The majority $(n=9,90 \%)$ had good $(50 \%)$ to very good $(40 \%)$ anaemia health literacy with one group rating fair. The size of the group did not appear to influence the healthy literacy scores as the largest $(n=10)$ and the smallest $(n=1)$ both had very good health literacy.

Following is a summary of the responses to each of the questions highlighting the themes and the average health literacy score.

\section{Q1. What is anaemia?}

Community members referred to the term anaemia as 'weak blood', 'low blood' or 'no blood'.

Health literacy score-fair (median 2.5, range 1-4).

\section{Q2. Why do you think people have weak blood?}

There was comprehensive discussion about the causes of 'weak blood'. The most common responses being, 'not eating enough fruit, not eating red meat, lack of vitamins, eating too much take away food and walking bare foot.'

There was some discussion around adverse health behaviors of mothers that included: 'mum wasn't eating good healthy food, maybe sniffing petrol, smoking cigarette or alcohol'. Causes of anaemia were also embedded in responses to Q1 that included 'worms', 'lack of good food', 'drinking black tea', 'walking in the rain with bare feet' and 'no iron in the body.'

One group described the benefits of pre-colonial way of life in preventing anaemia as, 'olden day's people use to live healthy and use healthy food from the bush and seafood, and it really helped our people with their health and their bloods.'

Health literacy score - good (median 3, range 2-4).

\section{Q3. What happens to people if they have weak blood?}

This question generated many responses that included, 'feel weak, feeling tired, no strength, no energy, weight gets low, underweight, sleepy, floppy, crying, ulcer, thrush, sore mouth, not eating much food, that worm gets in, don't feel like eating, get skinny, feel dizzy, sunken eyes, light/pale skin, no fluid in body, headache. One responder explained the effects on growth and development as 'because why people and kids slow learning and slow growing.'

Health literacy score - good level of understanding of what happens to people in the short to medium term but overall a limited understanding of long term implications of anaemia on daily living and educational attainment (median 3 , range $2-4$ ).

\section{Q4. How do they fix anaemia?}

This question generated many responses that included nutrition and medication management. Responses related to nutrition included: 'seafood, turtle, shells, mussels, half cooked meat, kangaroo meat, just the raw or half cooked that's what our people use to have their bloods strong; don't give kids tea, that means kids get weak; bush fruits and shop fruits, billy goat plum, wild plum, red green plums which have vitamins in them; bush foods.' There were two responses that included water could 'fix' anaemia.

Responses related to medications included: 'sometimes they give the kids medicine - worming medicine; sometimes they take blood at the clinic so they will give the right medicine, sometimes they get injection; sometimes they give them iron medicine, iron tablets or medicine from the clinic.'

Health literacy score - good (median 3, range 1-4). 


\section{Q5. How do they prevent anaemia?}

The responses focused on the importance of nutrition and environmental factors such as keeping your house clean. Many of the nutrition responses were similar to those reported in Q4 and included: "eating half cooked meat, iron, and good food, don't give black tea to kids, keep the house clean every day, bush foods, iron foods and fruits and vegetables"..

Health literacy score - fair (median 2, range 1-3).

\section{Q6. How do they know they have weak blood?}

This question generated many responses included in Q3 but not as comprehensively, e.g. 'tired, weak, sleepy, no strength and dizzy.'

Health literacy score - fair (median 2.5, range 2-4).

\section{Q7. How do they treat anaemia?}

Responses included a range of knowledge about specific medication, 'crushed up medicine tablet', 'that same medicine', 'medicine called albendazole', 'medicine' and 'iron injections and tablets'. The majority of the groups identified the treatment as iron injections or tablets and elaborated to suggest the need for bush foods to help treat anaemia.

Health literacy score - fair (median 2.5, range 1-4).

\section{Q8. What treatment would you prefer for yourself and what would you choose for your child?}

The majority of adults preferred to take iron tablets for three months but chose iron injections for their children (Table 3). Some of the response included: 'tablets make tummy upset, easy to have injection, kids don't like the liquid to drink, children don't like the taste, kids don't like injection but we force, would be better if you could hide it in food.'

Table 2. Community member focus groups and interview results

\begin{tabular}{|c|c|c|c|c|c|c|}
\hline Interview No. & Type of Interview & No. in Group & Male & Female & Score $\%$ & *Knowledge rating \\
\hline 1 & Focus group & 6 & 0 & 6 & 48 & Good \\
\hline 2 & Individual person & 1 & 0 & 1 & 43 & Good \\
\hline 3 & Focus group & 2 & 0 & 2 & 66 & Very Good \\
\hline 4 & Focus group & 6 & 0 & 6 & 59 & Good \\
\hline 5 & Focus group & 5 & 2 & 3 & 66 & Very Good \\
\hline 6 & Individual person & 1 & 0 & 1 & 68 & Very Good \\
\hline 7 & Focus group & 2 & 1 & 1 & 48 & Good \\
\hline 8 & Focus group & 4 & 0 & 4 & 43 & Good \\
\hline 9 & Focus group & 10 & 3 & 7 & 61 & Very Good \\
\hline 10 & Focus group & 2 & 1 & 1 & 53 & Good \\
\hline Total & & 39 & 7 & 32 & 55 & Good \\
\hline
\end{tabular}

*0-20\%=Poor, $21-40 \%=$ Fair, $41-60 \%=$ Good, $61-80 \%=$ Very Good, $81-100 \%=$ Excellent

Table 3. Community member responses to treatment

\begin{tabular}{|c|c|c|}
\hline Treatment option & Yourself (\%) & Your child (\%) \\
\hline No treatment & 0 & 0 \\
\hline Iron Injection & $3(19)$ & $9(60)$ \\
\hline Iron Tablets & $13(81)$ & $1(7)$ \\
\hline Liquid & 0 & $5(33)$ \\
\hline
\end{tabular}

Health literacy score - not assessed.

Table 4. Health practitioner focus groups and interview results

\begin{tabular}{|c|c|c|c|c|c|c|}
\hline Interview No. & Type of Interview & No. in Group & Male & Female & Score $\%$ & *Knowledge rating \\
\hline 1 & AHP & 1 & 0 & 1 & 75 & Very Good \\
\hline 2 & RAN & 1 & 1 & 0 & 78 & Very Good \\
\hline 3 & AHP & 1 & 0 & 1 & 59 & Good \\
\hline 4 & Trainee AHP & 1 & 1 & 0 & 63 & Very Good \\
\hline 5 & RAN & 1 & 0 & 1 & 77 & Very Good \\
\hline 6 & RAN \& ACWs & 3 & 0 & 3 & 80 & Excellent \\
\hline 7 & AHPs & 4 & 0 & 4 & 76 & Very Good \\
\hline Total & & 12 & 2 & 10 & 72 & Very Good \\
\hline
\end{tabular}

*0-20\%=Poor, $21-40 \%=$ Fair, $41-60 \%=$ Good, $61-80 \%=$ Very Good, $81-100 \%=$ Excellent 


\subsection{Health Practitioners}

Individual and group interviews were conducted with health practitioners in July and August 2013. Twelve health practitioners consented to be interviewed of which three were RANs, eight were AHPs and one was an ACW (Table 4). There was only one General Practitioner in the community at the time that declined to be interviewed. The style of interview conducted was different between the two health services. Practitioners at one health service preferred to be interviewed individually whereas practitioners from the other health service preferred to be interviewed in groups.

\section{Q1. What is anaemia?}

Most of the AHPs described anaemia as low blood, weak blood or no blood whereas the RANs responses described anaemia as "low haemoglobin". No health practitioners provided a response that made reference to a diagnostic range for children or adults.

Knowledge-good but responses were short, (median 3.5, range 3-5).

\section{Q2. What happens to people if they have anaemia?}

All the health practitioners described the symptoms of anaemia as, 'tired, weak, no energy, and dizzy,' however only the RANs made comments on growth that included: 'not growing well, so they are smaller than what we expect', 'they don't carry oxygen in their blood as well as someone who doesn't have anaemia', 'lots of infections and not able to get rid of infections easily' and 'not grow and develop as they normally would'. There was no discussion about how anaemia affects children's cognitive development and learning at school or how anaemia may impact on a person's daily living activities and ability to work.

Knowledge - very good understanding of acute symptoms (median 4, range 3-4). Responses did not cover:

- long term effects of anaemia on the cognitive development of children and the impact on learning ability at school.

- impact of anaemia on daily living.

\section{Q3. Who gets anaemia?}

Responses were very broad and included, "adults, kids and everyone.' Practitioners specializing in child health (3/12 interviewed) were the only ones to discuss the impact on pregnant women, preterm and low birth weight babies. One RAN mentioned 'blood loss through trauma,' 'people with other conditions like cancer.' No one discussed people with chronic kidney disease.

Knowledge - good (median 3, range 2-5). Generalist practitioners had limited knowledge on childhood risk factors for anaemia (i.e. low birth weight, preterm, and infection) or conditions in adults that may predispose to anaemia (i.e. pregnant women, chronic kidney disease).

\section{Q4. What causes anaemia?}

When discussing the causes of anaemia, most answers were focused around not eating the correct foods. One RAN talked about trauma and blood loss. One group focused on food security aspects that included gambling and not enough money to buy food. Infections were associated with anaemia but were not described as a cause of anaemia. There was no mention of worms or other conditions at this question, e.g. kidney disease, cancer.

Knowledge-good (median 3, range 2-4) about nutritional and food security issues associated with anaemia but there was a lack of comprehensive understanding of which conditions/infections predispose individuals to anaemia.

\section{Q5. How or when do we check if someone has anaemia?}

Venous and capillary blood was the most common answer to this question on how we check for anaemia. Responses to the question on when to check for anaemia stimulated responses such as 'every two weeks, three monthly check ups, 'if presenting with symptoms and if sick we check, otherwise when health check is due'.

Knowledge-good (median 3.5, range 2-4).

\section{Q6. What do you tell anaemic people about treatment?}

The information that health practitioners gave about anaemia treatment to people attending the health centre included oral and injectable iron as well as education on nutrition. Responses about nutrition education included, 'we give them education,' 'the first thing I talk about with them is what type of foods they are eating and I try to explain what foods will help bring up your haemoglobin.'

Knowledge - Good (median 3, range 2-4) of treatment options and the need to discuss nutrition. Discussion about the cause of the individual's anaemia, side effects of treatment and length of treatment were not mentioned.

\section{Q7. What treatment do you offer anaemic people?}

Health practitioners in general had no preference about which form of iron treatment offered. All practitioners stated that they gave the individual or parent the option and administered whichever drug was chosen. Responses included, 'we give injection to children or medicine if the child's not happy for us to give injection,' 'we might give oral iron or injections, depends on the family and what is going to be easy for them,' 'some people don't like the tablet because it makes the colour of the gula (faeces) change, go black in colour, make them feel yaka manymak (no good) scared, they prefer to have needle instead.' One RAN discussed folic acid and said that she administered medication according to the CARPA manual. Deworming was only mentioned by one RAN and one AHP. The AHPs highlighted the need for the parents to be responsible in assisting the clinic to administer the medicine.

Knowledge-very good (median 4, range 3-5) of available treatments however, only one practitioner made reference to giving what was recommended in CARPA as the treatment options differ depending on the haemoglobin result. The majority of practitioners did not mention deworming as part of the treatment regimen. 


\section{Q8. Do you talk about food/diet?}

All respondents stated that they discussed nutrition however, the AHPs provided more detail. Responses included, 'for Yolngu people we get food from the bush, sea like turtle, kangaroo, fish and goanna,' 'it tells that person with anaemia should have meat- that it is half cooked or vegetables and also there is a roots from the bush or grass that there is a medicine to keep them strong or gives strength.'

Knowledge-not assessed.

\section{Q9. Do people take the treatment?}

This question generated many responses that inferred how difficult it can be to take iron treatment and that there are social issues that need to be considered. Responses included: 'I don't know, maybe they do,' 'yes, but the compliance isn't as good as I'd like,' 'it's hard one for us here, we work with mothers often who are struggling anyway, so raising kids is hard for them they are the ones that have big problems.'

Knowledge - not assessed.

\section{Q10. How do you find out if the anaemia has gone away?}

This question was asked in the first three interviews and triggered responses about recalls in the electronic health record. The question was adapted to, 'When do you bring people back to find out if their anaemia is improving? Responses included, 'it depends on their treatment', 'with oral iron we go one month and then we test again', 'both for children and adults it would be after three months' and 'if it is real low, very quickly, we monitor it each day and then we do three monthly checks'. 2-5)

Knowledge - Very good understanding (median 4, range

\section{Q11. When you give treatment for anaemia do you put a recall in for when they need to be followed up?}

Most respondents knew that a recall was triggered when a low $\mathrm{Hb}$ result was entered but did not identify consistent processes. The majority of respondents mentioned that they created a manual recall and entered the time frame that they wished to review the individual in manually. Only one RAN was able to clearly describe how the recall system and anaemia care plans worked. The practitioner identified the complexity of the anaemia plans and the recall system and describes the whole process as 'a bit of overkill' and noted that other staff and programs within the health system have encountered challenges in using the system effectively, one of the clinics found anaemia (in Communicare) "too overwhelming to deal with."

Knowledge - Good understanding (median 3.5, range 3-5) of generating a recall however, only one mentioned the anaemia care plan. The care plan prompt appears when a low $\mathrm{Hb}$ is entered but you need to click on the care plan prompt to fill out the details. The care plan provides the practitioner with all the treatment and other information that should be provided at that visit.

\section{Extra Question - What would you do if a person had a $\mathrm{Hb}$ of 108 ?}

During the research translation week in December 2013, 13 health practitioners were asked to complete a question on what they would do if a person with an $\mathrm{Hb}$ of 108 presented to the clinic. It was explained that this figure of 108 was just below the normal value of 110 . Three responses were provided to choose from and more than one response could be circled (Table 5). The majority of health staff would not treat a person with an $\mathrm{Hb}$ of 108 but have them return in 2-4 weeks to re-check their $\mathrm{Hb}$ level.

Knowledge - According to the CARPA standard treatment manual an $\mathrm{Hb}<110 \mathrm{~g} / \mathrm{L}$ would be considered iron deficient if aged $\geq 1$ year.

Table 5. Health Practitioner responses for $\mathrm{Hb} 108 \mathrm{~g} / \mathrm{L}$

\begin{tabular}{|c|c|}
\hline Responses & No. responses $(\%)$ \\
\hline Come back in 2-4 weeks & $10(77)$ \\
\hline Talk about iron rich foods & $8(62)$ \\
\hline Treat with iron medicine & $3(23)$ \\
\hline Responders inserted - deworm & $3(23)$ \\
\hline Could this person be iron deficient? & $\begin{array}{c}\text { Yes } \\
6(46)\end{array}$ \\
\hline
\end{tabular}

\section{Discussion}

Anaemia health literacy on average was 'good' for community members and 'very good' for health practitioners. Community members focused mainly on diet as a preventative and curative measure providing similar descriptions to that of the AHPs. Despite a 'good' level of community anaemia knowledge, there was no evidence that this knowledge translated into the dietary intake of children who had simultaneously participated in a 4-day food diary collection published previously. [20] It is possible that food insecurity and knowledge [26] of how often iron rich foods should be consumed were contributing factors to the nutrient deficient diets of children that were not investigated in this study. With the increasing availability and affordability of healthy food options in local community stores a randomized controlled trial is currently being implemented to determine if a reduction in healthy food prices influences dietary behaviour changes. [27]

Health practitioners' knowledge of follow-up procedures varied ranging from fair to excellent. The introduction of electronic health records over the last 10 years has greatly improved the generation of recall lists to follow-up participants that have been flagged for review. From the health practitioners interviewed, a number of different ways to enter data and generate recalls were described. A standard procedure for entering data and generating recalls with improvements to the prompts that incorporate the recommended treatment and brief interventions from CARPA standard treatment manual would assist the health practitioners to implement what is recommended in the guidelines more effectively. 
Noteworthy was the health practitioner's response to the extra question on $\mathrm{Hb} 108 \mathrm{~g} / \mathrm{L}$ if $110 \mathrm{~g} / \mathrm{L}$ was considered normal. CARPA standard treatment manual, the best practice guidelines used by remote $\mathrm{PHC}$ services, indicates that all anaemia (low $\mathrm{Hb}$ for age) be treated as iron deficient anaemia. With an $\mathrm{Hb}$ of $108 \mathrm{~g} / \mathrm{L}$ the CARPA manual recommends iron treatment. The responses included almost an equal number of practitioners who diagnosed iron deficiency as those who said it was not iron deficiency. The introduction of continuous quality improvement (CQI) activities enables health services to monitor best practice and make improvements where gaps exist has helped to identify and address systematic barriers and areas of poor adherence to best practice guidelines for some, but not all commonly seen conditions. [28]

Community members were more likely to take oral iron therapy for themselves but indicated that they would prefer an iron injection for their child as the current oral iron therapy used causes gastrointestinal upsets and is not palatable for children to take. A PHC service in a different NT region mixes orange juice with the oral iron liquid [29] to improve the taste and uptake of treatment however; this is not supported by the best practice guidelines.

The interview guide developed for this study may be useful for other health services to assess the knowledge of childhood anaemia amongst staff and community members. Offering group or individual interview methods was useful to increase participation rates. Very few community members or health practitioners declined to be interviewed, however not all interviewees participated in the discussions, a limitation for this type of methodology. Focus group facilitators were trained in interview methods to enable them to deal with outspoken respondents and those who were hesitant to respond however this does not mean that all group participants respond equally.

This project was able to establish that focus groups and individual interviews conducted with community members and health practitioners obtained informative responses on anaemia health literacy and knowledge of best practice guidelines. The responses provided insights to barriers affecting the implementation of anaemia screening and treatment guidelines that can be used to initiate change and direct further research enquires.

\section{Conclusions}

Anaemia is a complex condition with multiple risk factors associated with the development of disease throughout the life span. Anaemia health literacy and knowledge of best practice guidelines were good but are not being translated into practice. Risk factors commence at conception and continue throughout adulthood providing a number of opportunities to introduce prevention and management strategies. With high childhood anaemia rates in the NT and poor implementation of best practice screening and treatment guidelines, innovative and culturally acceptable prevention and management strategies should be given a high priority.

\section{Acknowledgements}

We would like to acknowledge the passing of contributing author Leanne Bundhula Dhurrkay who tragically deceased during the writing of this paper. We would also like to acknowledge the remote Aboriginal community and health services for participating in the study.

\section{REFERENCES}

[1] Barclay L, Kruske S, Bar-Zeev S, Steenkamp M, Josif C, et al. (2014) Improving Aboriginal maternal and infant health services in the 'Top End' of Australia; synthesis of the findings of a health services research program aimed at engaging stakeholders, developing research capacity and embedding change. BMC Health Serv Res 14: 241.

[2] Australian Institute of Health and Welfare (2012) Australia's health 2012. Canberra: AIHW.

[3] World Health Organization (2008) worldwide prevalence of anaemia 1993-2005.

[4] Rumbold AR, Bailie RS, Si D, Dowden MC, Kennedy CM, et al. (2011) Delivery of maternal health care in Indigenous primary care services: baseline data for an ongoing quality improvement initiative. BMC Pregnancy Childbirth 11: 16.

[5] Northern Territory Department of Health and Families (2009) Healthy Under Five Kids Data Collection (GAA) Program.

[6] Central Australian Rural Practitioners Association (2011) the CARPA Reference Manual (4th Edition).

[7] Corwin EJ, Murray-Kolb LE, Beard JL (2003) Low hemoglobin level is a risk factor for postpartum depression. $\mathrm{J}$ Nutr 133: 4139-4142.

[8] Engle PL, Black MM, Behrman JR, Cabral de Mello M, Gertler PJ, et al. (2007) Strategies to avoid the loss of developmental potential in more than 200 million children in the developing world. Lancet 369: 229-242.

[9] Brewster DR (2004) Iron deficiency in minority groups in Australia. Journal of Paediatrics and Child Health 40: 422-423.

[10] Care ACoSaQiH (2014) Health literacy:Taking action to improve safety and quality. Sydney: ACSQHC.

[11] Dewalt DA, Berkman ND, Sheridan S, Lohr KN, Pignone MP (2004) Literacy and health outcomes: a systematic review of the literature. J Gen Intern Med 19: 1228-1239.

[12] Bailie R, Matthews V, Sheahan A (2014) Trends over Time: Key Indicator of Priority Evience-Practice Gaps in Child Health (2007-2013).

[13] Bailie R, Matthews V, Sheahan A (2012-2013) Engaging stakeholders in identifying priority evidence-practice gaps and strategies for improvement in primary health care (The 
ESP Project), National child health care report.

[14] Bar-Zeev SJ, Kruske SG, Barclay LM, Bar-Zeev N, Kildea SV (2013) Adherence to management guidelines for growth faltering and anaemia in remote dwelling Australian Aboriginal infants and barriers to health service delivery. BMC Health Serv Res 13: 250.

[15] East Arnhem Shire Council (2012) Galiwin'ku.

[16] Government A (2012) Closing the Gap:Primister's Report.

[17] East Arnhem Regional Council (2012) Galiwin'ku.

[18] Andrews A, Kearns T, Connors C, Parker C, Currie B, et al. (2009) A regional initiative to reduce skin infections amongst Aboriginal children living in remote communities of the Northern Territory, Australia. PLoS Negl Trop Dis 3: e554. doi:510.1371/journal.pntd.0000554.

[19] Kearns TM, Speare R, Cheng AC, McCarthy J, Carapetis JR, et al. (2015) Impact of an Ivermectin Mass Drug Administration on Scabies Prevalence in a Remote Australian Aboriginal Community. PLoS Negl Trop Dis 9: e0004151.

[20] Liberato SC, Kearns T, Ward F, Brimblecombe J (2015) Use of electronic visual recording to aid assessment of dietary intake of Australian Aboriginal children living in remote communities. Aust N Z J Public Health.

[21] Kidney Health Australia (2008) All About Anaemia.

[22] Raising Children Network (Australia) Limited (2006-2014)
Anaemia.

[23] Donovan RJ, Spark R (1997) towards guidelines for survey research in remote Aboriginal communities. Aust $\mathrm{N} \mathrm{Z} \mathrm{J}$ Public Health 21: 89-95.

[24] Northern Terrirotry Government (2007) Remote Health Atlas - Client Recall Systems. In: Department of Health and Families, editor.

[25] Central Australian Rural Practitioners Association Editorial Committee, editor (2009) CARPA Standard Treatment Manual: a clinic manual for primary health care practitioners in remote and rural communities in Central and Northern Australia. 5th ed: Central Australian Rural Practitioners Association.

[26] Rogers A, Ferguson M, Ritchie J, Van Den Boogaard C, Brimblecombe J (2016) Strengthening food systems with remote Indigenous Australians: stakeholders' perspectives. Health Promot Int.

[27] Brimblecombe J, Ferguson M, Liberato S, Ball K, Moodie M, et al. (2013) Stores Healthy Options Project in Remote Indigenous Communities (SHOP@RIC): a protocol of a randomised trial promoting healthy food and beverage purchases through price discounts and in-store nutrition education. BMC Public Health 13: 744.

[28] Clarke Aa (2013) Evaluation of the Northern Territory Continuous Quality Improvement (CQI) Investment Strategy: Summary report. Canberra: Department of Health.

[29] Health S (2001) Barunga School Program. Sunrise Health. 